\title{
Aspectos morfológicos e funcionais dos autoimplantes esplênicos em ratos tratados com oxigenio hiperbárico
}

\section{Splenic autoimplant and hyperbaric oxygen therapy in rats}

\author{
Isabel Cristina Andreatta lemos Paulo, ACBC-ES; Alcino lázaro da Silva, ECBC-MG²; Cláudio Piras, ACBC-ES 3 ; \\ Bernardo Faria Ramos4; Fernando Roberto Zanetti5; Danilo Nagib Salomão Paulo, TCBC-eS6
}

\author{
R E S U M O
}

\begin{abstract}
Objetivo: Estudar aspectos morfológicos e funcionais dos autoimplantes esplênicos de ratos submetidos ou não à oxigenioterapia hiperbárica (OHB). Métodos: Foram estudados em dois períodos distintos 105 ratos Wistar. No período mediato $(n=56)$ os animais foram avaliados até $011^{\circ}$ dia de pós-operatório, e no período tardio $(n=49)$, até o $70^{\circ}$ dia. Em cada período os ratos foram distribuídos nos grupos: A- Simulação, B- Autoimplante esplênico, tratados com oxigênio hiperbárico ou não. Nos animais do Grupo A realizou-se apenas manipulação do baço. Nos animais do Grupo B realizou-se esplenectomia total e a seguir quatro fragmentos do baço foram implantados no grande omento. Em todos os animais foram dosados os lípides e imunoglobulinas e contadas as plaquetas e os corpúsculos de Howell-Jolly no pré-operatório e no $11^{\circ}$ ou $70^{\circ}$ dia de pós-operatório. O baço dos animais do Grupo A e os autoimplantes dos animais do Grupo B foram retirados e enviados para avaliação morfológica. Resultados: No grupo B11nt houve aumento do colesterol total, LDL-colesterol, VLDL-colesterol e triglicérides. No grupo B70nt houve aumento do colesterol total e LDLcolesterol. Nos grupos tratados não houve alterações lipídicas. A IgM caiu nos grupos B e não alterou nos grupos A. Os corpúsculos de Howell - Jolly foram menos freqüentes nos grupos Bt que nos grupos Bnt. As plaquetas aumentaram nos grupos B11t e B11nt e não se alteraram nos demais grupos. A viabilidade microscópica dos grupos Bt foi melhor que a dos grupos Bnt. Conclusão: Os autoimplantes esplênicos dos animais tratados com OHB apresentaram melhor função e viabilidade do que os autoimplantes dos animais não tratados.
\end{abstract}

Descritores: Baço/cirurgia. Baço/metabolismo. Esplenectomia/métodos. Esplenectomia/efeitos adversos. Oxigenação hiperbárica.

\section{INTRODUÇÃO}

\begin{abstract}
A esplenectomia total pode induzir várias complicações'. Destas, a mais temida é a infecção fulminante após a esplenectomia ${ }^{2}$ que é provocada por diferentes bactérias ${ }^{3}$. As complicações infecciosas, após a retirada do baço, foram também observadas em animais de experimentação ${ }^{4}$. Além dessas complicações, têm sido relatadas, após esplenectomia, alterações no metabolismo lipídico tanto em seres humano ${ }^{5,6}$ quanto em animais de experimentação ${ }^{7-13}$. Por essas razões têm sido valorizadas as operações conservadoras sobre o baço. Destas, os autoimplantes esplênicos são os mais controvertidos sob o ponto de vista funcional e cumprem parcialmente a função do baço no metabolismo lipídico ${ }^{12}$. Os autoimplantes passam a ter função mais eficaz após a $16^{\mathrm{a}}$ semana da cirurgia ${ }^{14}$. Por esse motivo seria interessante utilizar um método para melho-
\end{abstract}

rar a função dos autoimplantes esplênicos na tentativa de evitar complicações, inclusive o óbito.

A oxigenoterapia hiperbárica (OHB) é um método terapêutico no qual o indivíduo é submetido à inalação intermitente em um ambiente com $100 \%$ de Oxigênio $\left(\mathrm{O}_{2}\right)$ a uma pressão maior que a atmosférica, no interior de uma câmara hiperbárica. O efeito primário da OHB consiste em aumentar a pressão parcial de oxigênio $\left(\mathrm{PO}_{2}\right)$ no plasma. Essa modalidade terapêutica tem sido utilizada no tratamento de várias doenças. No Brasil, a Resolução CFM $1457 / 95$ do Conselho Federal de Medicina ${ }^{15}$ regulamentou seu uso nos seguintes casos: embolias gasosas, doença descompressiva, embolias traumáticas pelo ar, envenenamento por monóxido de carbono ou inalação de fumaça, envenenamento por cianeto ou derivados cianídricos, gangrena gasosa, doença de Fournier, celulites, fasciites, miosites, isquemias agudas traumáticas, vasculites agudas,

Trabalho realizado no Laboratório da Disciplina de Fundamentos da Cirurgia e no Centro de Pesquisa, Escola Superior de Ciências, Santa Casa de Misericórdia de Vitória- ES, Brasil.

1. Professora Adjunta da Disciplina de Cirurgia da Escola Superior de Ciências da Santa Casa de Misericórdia de Vitória-ES-BR; 2. Professor Emérito da Faculdade de Medicina da Universidade Federal de Minas Gerais- MG-BR; 3. Professor Adjunto da Disciplina de Cirurgia da Escola Superior de Ciências da Santa Casa de Misericórdia de Vitória-ES-BR; 4. Médico residente da Faculdade de Medicina da Universidade de São Paulo; 5. Médico residente da Unicamp- SP-BR; 6. Professor Titular da Disciplina de Fundamentos da Cirurgia da Escola Superior de Ciências da Santa Casa de Misericórdia de Vitória-ES-BR. 
queimaduras térmicas ou elétricas, úlceras de pele, lesões pé-diabéticos, escaras de decúbito, úlcera por vasculites autoimunes, deiscências de suturas, ostemielite, osteorradionecrose, lesões actínicas de mucosas, retalhos ou enxertos comprometidos ou de risco e anemia aguda, nos casos de impossibilidade de transfusão sanguínea. A $\mathrm{OHB}$, no entanto, apresenta efeitos colaterais ${ }^{16}$ decorrentes da variação de pressão e/ou da toxicidade do oxigênio, e contra-indicações absolutas e relativas. São elas : a- Absolutas: uso de medicamentos como Doxorrubicin, Dissulfiram e, Cis-Platinum, pneumotórax não-tratado, gravidez; b- Relativas: infecções das vias aéreas superiores, DPOC com retenção de $\mathrm{CO} 2$, hipertermia, história de pneumotórax espontâneo, cirurgia prévia em ouvido, esferocitose congênita, infecção viral-fase aguda. Todas merecem avaliação antes da realização da OHB.

Em animais de experimentação demonstrou-se que a OHB tem efeito angiogênico, ${ }^{17,18}$ estimula a formação de circulação colateral, ${ }^{19}$ melhora a viabilidade de transplantes das ilhotas pancreáticas, ${ }^{20}$ acelera a cicatrização do baço após a ligadura simultânea da artéria e veia esplênicas, ${ }^{21}$ atenua os efeitos deletérios sobre o fígado e o baço de ratos submetidos à ligadura das veias hepáticas, ${ }^{22}$ além de atuar beneficamente em processos inflamatórios: pancreatite, ${ }^{23-25}$ colite, ${ }^{26,27}$ hepatite crônica ${ }^{28}$ e aterosclerose ${ }^{29}$. Trabalho recente mostrou que essa modalidade terapêutica melhora a função lipídica e a viabilidade do pólo inferior do baço no pós-operatório ${ }^{30}$.

Considerando os referidos efeitos da OHB, levantou-se a hipótese de que esse método poderia melhorar a viabilidade e a função dos autoimplantes, Daí foi realizado este trabalho com os objetivos de estudar os aspectos morfológicos e funcionais dos autoimplantes esplênicos em ratos submetidos ou não à oxigenoterapia hiperbárica.

\section{MÉTODOS}

O presente trabalho foi aprovado pelo Comitê de Ética em Pesquisa da Universidade Federal de Minas Gerais conforme documento de $n^{\circ}$ ETIC 100/2006.

Foram estudados em dois períodos distintos 105 ratos machos, Wistar, pesando $251,6 \mathrm{~g} \pm 29,5 \mathrm{~g}$. No período mediato $(n=56)$, os animais foram avaliados até o $11^{\circ}$ dia de pós-operatório, e no período tardio $(n=49)$ foram avaliados até o $70^{\circ}$ dia. Em cada período os ratos foram distribuídos nos grupos: A- Simulação, BAutoimplante esplênico, tratados com oxigênio hiperbárico (t): A11t $(n=10), B 11 t(n=15), A 70 t(n=10)$, B70t $(n=$ 11) ou não(nt) (A11nt (n=10), B11nt $(n=21)$, A70nt ( $n=$ 10 , B70nt $(n=18)$. Os animais foram alocados em gaiolas coletivas com capacidade para cinco animais. O fundo das gaiolas recebeu forração de maravalhas de madeira; e o teto, grade de metal. Durante todo o experimento foram alimentados com ração comercial granula- da para animais de laboratório (Moinho Primor ${ }^{\circledR}$ MP-77, São Paulo) e água à vontade.

\section{Técnicas}

Após jejum de 12 horas, os ratos receberam injeção de 25 mg/kg de Cloridrato de Quetamina no músculo da pata posterior, foram pesados (balança eletrônica Filizola ${ }^{\circledR}$-sensibilidade de $1 \mathrm{~g}$ ) e submetidos à punção cardíaca transtorácica para colheita de 1,2 mL de sangue. Cada animal foi identificado com uma marca na orelha e devolvido à sua gaiola de origem. O sangue colhido foi dividido igualmente em um frasco com ácido etilenodiamino tetraacético (EDTA) para contagem das hemácias, plaquetas e leucócitos(equipamento automatizado "Cell-Dyn" 3700 da "Abott" ${ }^{\circledR}$ Illinois-USA), e em outro frasco sem EDTA para dosagem de imunoglobulinas e lípides. A dosagem das imunoglobulinas foi feita pelo método de turbidimetria, com o aparelho "Behring Turbitimer" ${ }^{\circledR}$ (Marburg-Alemanha), e a dos lípides no aparelho "Dimension AR DADE BEHRING" ${ }^{\circledR}$ (Illinois, EUA). Para contagem dos corpúsculos de Howell Jolly em cada 10 campos, foram feitas lâminas de esfregaço sanguíneo que foram analisadas em microscópio "Olympus" ${ }^{\circledR}$ DX40 com objetiva de $100 \mathrm{mHz}$.

Três dias após a colheita de sangue, os animais anestesiados com uma mistura de cloridrato de xilazina (2,5 mg/Kg peso) e cloridrato de quetamina(50 mg/Kg peso) e após antissepsia da parede abdominal com álcool iodado foram submetidos a laparotomia mediana com cerca de $2,5 \mathrm{~cm}$ de comprimento e exame da cavidade abdominal. Nos animais do grupo $A(A 11 t, A 11 n t, A 70 t, A 70 n t)$, foi realizada a manipulação do baço. Nos animais do grupo $B($ B11t, B11nt, B70t, B70nt), foi realizado o autoimplante esplênico da seguinte maneira: após três ligaduras rentes ao baço com fio de algodão 3-0, esse órgão foi retirado, dividido em duas metades semelhantes, cada qual pesada individualmente. A metade inferior foi subdividida em quatro fragmentos (fatias) de tamanhos iguais. Cada fragmento foi colocado separadamente sobre o omento maior e ali fixado com um ponto separado simples, mononáilon ${ }^{\circledR}$ 4-0. (Figura 1). Após a operação proposta, a parede abdominal foi suturada em dois planos.

A OHB foi realizada com o seguinte protocolo: imediatamente após a operação os ratos foram colocados na câmara hiperbárica ${ }^{21}$ onde foi realizada uma compressão gradual até 2,5 atmosferas, num período de 15 minutos. Nessa pressão foram mantidos por 90 minutos; a seguir foi realizada a descompressão gradual da câmara num período de 15 minutos. Esse tratamento foi realizado duas vezes por dia, com intervalo de 12 horas, por três dias, e uma vez por dia durante sete dias. A câmara hiperbárica utilizada foi a (CHV- Vitória Montadora e distribuidora LtdaVitória-ES) com formato cilindro capsular construída com aço carbono: 1- Entrada e saída da câmara; 2- Válvula para escape do oxigênio; 3- Termômetro; 4-Manômetro; 5- Tubo para entrada de oxigênio no interior da câmara; 6Visor para observação dos animais no interior da câmara; 


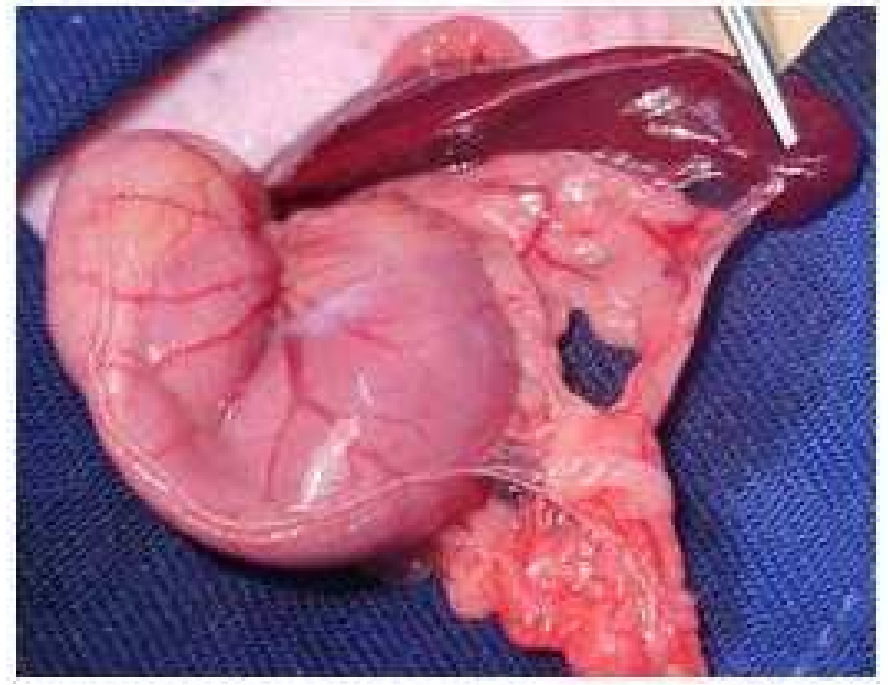

A

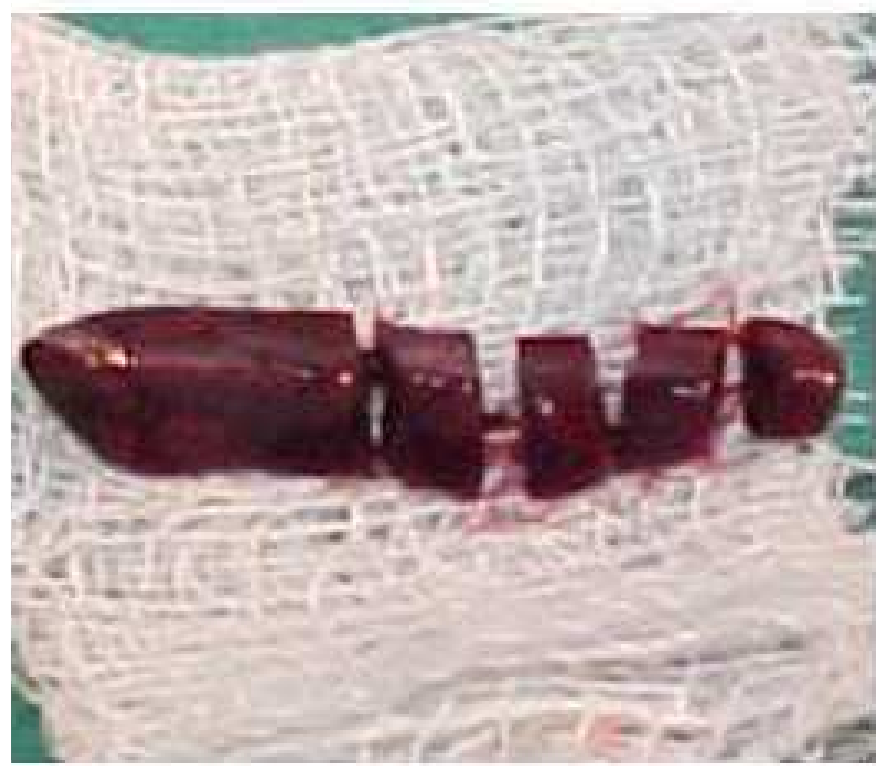

C

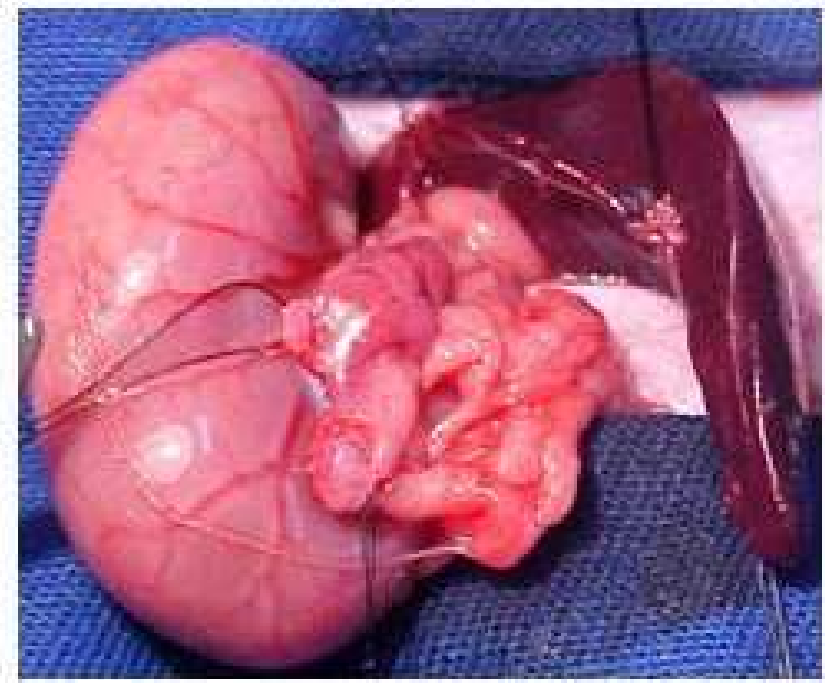

B

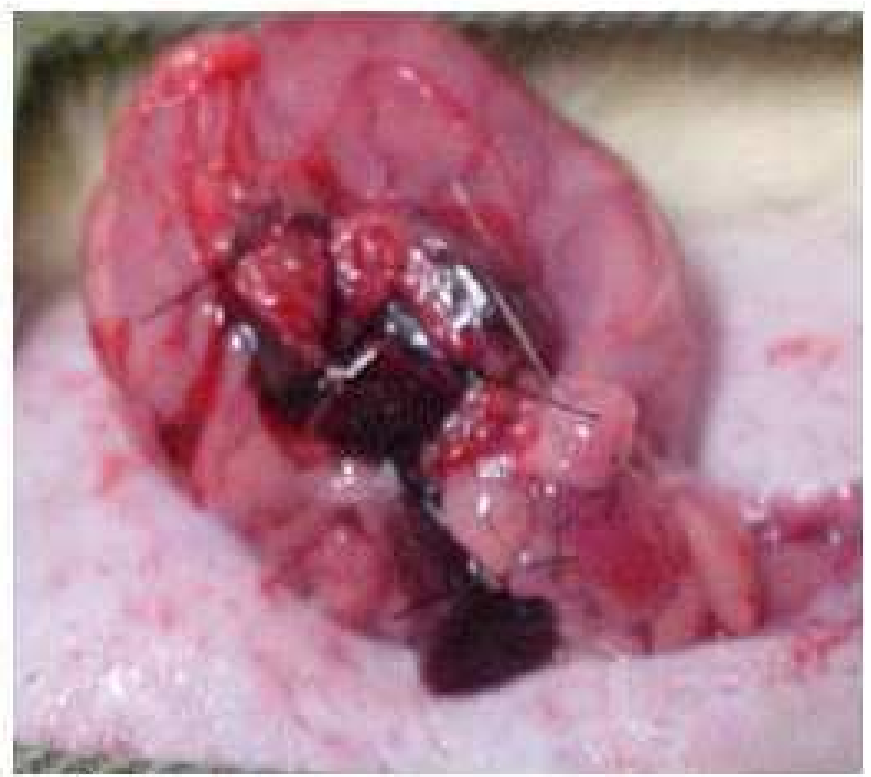

D

Figura 1 - Sequência da operação de auto-implante.a) exposição do baço para a esplenectomia ; b) realização de três ligaduras rentes ao baço para a esplenectomia; c) baço seccionado ao meio sobre uma gaze. A metade superior está íntegra; e a metade inferior, cortada em quatro fragmentos.; d) implantação dos quatro fragmentos no omento maior por meio de uma sutura com mononáilon ${ }^{\circledast} 4.0$.

7- Tampa oclusora da câmara. A Câmara tem $27 \mathrm{~cm}$ de largura, $51 \mathrm{~cm}$ de comprimento e 1,5 cm de espessura (Figura 2).

No pós-operatório imediato, os ratos receberam paracetamol na dose de $200 \mathrm{mg} / \mathrm{Kg}$, via oral, dissolvida na água do bebedouro, dieta livre e água a vontade. No $11^{\circ} \mathrm{PO}$ ou no $70^{\circ} \mathrm{PO}$, após um período de jejum de 12 horas, todos foram submetidos à nova coIheita de sangue para repetição dos exames laboratoriais, A seguir os animais foram mortos, com dose letal de pentobarbital sódico na cavidade abdominal. Foram pesados e submetidos a uma incisão em " $U$ " invertido na parede abdominal para abertura e exame da cavidade peritonial. No exame macroscópico foram verificados principalmente o aspecto do baço e o dos autoimplantes. Foram considerados macroscopicamente normais os baços e auto-implantes que apresentaram cor, consistência e viabilidade (ausência de necrose) de um baço normal. O baço e os auto-implantes foram retirados e pesados com precisão de 0,001g, e fotografados. Para exame microscópico o baço e os remanescentes esplênicos foram colocados em solução de formol a $10 \%$. A seguir incluídos em blocos de parafina e cortados em micrótomo rotativo com três micrômetros de espessura. Os cortes histológicos foram estendidos sobre lâminas de vidro e colocados em estufa a $58^{\circ} \mathrm{C}$ por 24 horas. 


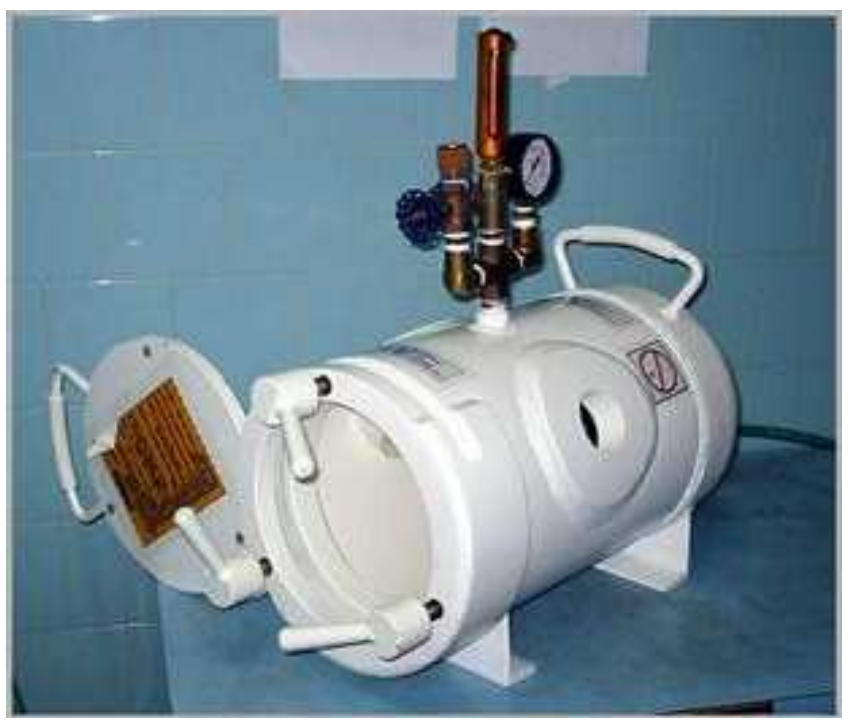

Figura 2 - Câmara hiperbárica (CHV - Vitória Montadora e distribuidora Ltda- Vitória-ES) com formato cilindro capsular construída com aço carbono: 1 - Entrada e saída da câmara; 2 - Válvula para escape do oxigênio; 3 - Termômetro; 4 - Manômetro; 5 - Tubo para entrada de oxigênio no interior da câmara; 6 - Visor para observação dos animais no interior da câmara; 7 - Tampa oclusora da câmara. A Câmara tem 27 cm de largura, $51 \mathrm{~cm}$ de comprimento e 1,5 cm de espessura.

Aderidos às lâminas, esses cortes foram desparafinizados em xilol e corados pelos métodos hematoxilina-eosina (H\&E) e tricrômico de Masson. A microscopia foi realizada por dois patologistas em microscópio binocular, sendo que os patologistas desconheciam o subgrupo a que pertencia o animal. Os cortes foram analisados quanto às alterações morfológicas. Os parâmetros observados foram: hemossiderose, hematopoese extramedular, hemofagocitose na polpa vermelha, presença de macrófagos, linfócitos, fibrose e áreas de necrose coagulativa. Foi considerado microscopicamente normal o tecido esplênico que não apresentava necrose, principalmente, fibrose e depleção celular.

Foram utilizados os seguintes testes estatísticos : a- Anova para amostras relacionadas para comparar os pesos do pré-operatório com os do pós-operatório num mesmo grupo; b- o teste t para mostras independentes para comparar o peso entre os dois grupos de animais; c- o teste t de Student para amostras relacionadas a fim de comparar os valores do colesterol e frações e triglicérides, imunoglobulinas e plaquetas do pré-operatório com os do pós-operatório.; d- o teste do qui-quadrado para comparar o número de corpúsculos de Howell Jolly entre os diferentes grupos. O teste exato de Fisher foi utilizado quando uma das freqüências esperadas foi inferior a cinco.

Os valores de " $p$ " foram considerados significantes quando iguais ou menores que 0,05 ou $5 \%$.

\section{RESULTADOS}

Não houve no pré-operatório diferença estatisticamente significante entre os pesos dos grupos $A$ e $B$, dos períodos mediato e tardio, tratados ou não com OHB. Houve diminuição de peso em todos os grupos no $11^{\circ}$ dia de pós-operatório, que foi significante no grupo $\mathrm{A} 11 \mathrm{t}(\mathrm{p}=0,05)$ e B11t $(p=0,0001)$. Houve aumento de peso no $70^{\circ}$ dia de pós-operatório nos grupos $A 70 n t(p=0,03), A 70 t(p=0,0000)$, B70t e B70nt( $p=0,0000)$.

O peso médio dos baços nos grupos B11t e B1 $1 \mathrm{nt}$ foi de $814 \mathrm{mg} \pm 11,1$, e o peso médio dos autoimplantes, no transoperatório, foi de $408 \mathrm{~g} \pm 51,2 \mathrm{~g}$, o que representou cerca de $50,12 \%$. O peso médio dos baços nos grupos B70t e B70nt, no transoperatório, foi de 863,09 g $\pm 132,84$ g. O peso médio dos autoimplantes foi de $410 \mathrm{~g} \pm 79,37 \mathrm{~g}$, o que representou cerca de $47,5 \%$ do baço.

Nos grupos A11t e A11nt, os níveis de colesterol total e frações não apresentaram alterações significantes no $11^{\circ} \mathrm{PO}$ em relação ao pré-operatório. No grupo B11nt houve aumento do colesterol total $(p=0,0068)$, LDLcolesterol $(p=0,002)$, VLDL-colesterol e triglicérides( $p=0,0033$ ). No grupo B70nt houve aumento do colesterol total $(p=0,0007)$ e LDL-colesterol $(p=0,0000)$. A VLDLcolesterol e triglicérides não se alteraram. Nos grupos B11t e B70t não houve alterações dos lípides (Tabela 1).

As IgG e IgA não apresentaram alterações significantes nos diferentes grupos. A IgM caiu nos grupos $B(p=0,0000)$ e não se alterou nos grupos $A$.

Os corpúsculos de Howell Jolly não apareceram nos grupos $A$, tratados ou não com oxigênio hiperbárico e não diferiram entre os grupos B70nt e B70t. Nos grupos B11t e B70t, o número de corpúsculos foi de $32 \mathrm{em} 19$ ratos, e nos grupos $B 11$ nt e B70nt foi de 73 em 19 ratos $(p=0,03)$.

Nos grupos A11 e A70, tratados ou não com $\mathrm{OHB}$, os baços apresentavam aspecto macroscópico normal com poucas aderências à parede abdominal ou vísceras adjacentes. Nos grupos B11 e B70, tratados ou não com oxigênio hiperbárico, foram observadas aderências mais intensas e firmes entre os locais dos auto-implantes e as alças intestinais. Em três casos do grupo B11nt e em dois casos do grupo B11t foi observada degeneração dos autoimplantes com secreção local, espessa e amarelada. Algumas vezes os autoimplantes estavam firmemente aderidos ao omento e alças intestinais, o que dificultava as suas dissecções e análises macroscópicas.

O aspecto microscópico do baço nos grupos A11 e A70, tratados ou não com oxigênio hiperbárico, foi semelhante. Observou-se hemossiderose, hematopoese extramedular e presença de hemofagocitose na polpa vermelha. Os autoimplantes do grupo B11t foi mais viável que os do grupo B1 1nt. Isso porque houve menor intensidade de necrose coagulativa, de fibrose periesplênica e de depleção linfóide no grupo tratado que no não tratado (Figura 3). O tecido periesplênico residual apresentou-se mais 
Tabela 1 - Valores dos lípides em mg/dL (média „desvio padrão) nos animais dos grupos simulação e autoimplante esplênico, submetidos ou não à oxigenoterapia hiperbárica no pós-operatório.

\begin{tabular}{lcccccccccc}
\hline Grupo & \multicolumn{2}{c}{ Colesterol } & \multicolumn{2}{c}{ HDL } & \multicolumn{2}{c}{ LDL } & \multicolumn{2}{c}{ VLDL } & \multicolumn{2}{c}{ Triglicérides } \\
& Pré & Pós & Pré & Pós & Pré & Pós & Pré & Pós & Pré & Pós \\
\hline A11nt & $53,1 \pm 6,5$ & $52,7 \pm 6,5$ & $21,5 \pm 2,7$ & $21,7 \pm 2,6$ & $22,4 \pm 2,7$ & $21,9 \pm 2,8$ & $9,0 \pm 1,5$ & $9,0 \pm 1,2$ & $45,8 \pm 7,1$ & $45,3 \pm 6,3$ \\
A11t & $55,6 \pm 6,3$ & $55,4 \pm 6,8$ & $22,5 \pm 2,3$ & $22,6 \pm 2,4$ & $23,7 \pm 2,6$ & $23,3 \pm 3,0$ & $9,3 \pm 1,4$ & $9,4 \pm 1,4$ & $46,7 \pm 7,3$ & $47,0 \pm 7,3$ \\
A70nt & $53,2 \pm 6,1$ & $53,1 \pm 6,2$ & $21,8 \pm 2,0$ & $21,8 \pm 2,5$ & $21,7 \pm 3,0$ & $21,5 \pm 3,1$ & $9,6 \pm 1,4$ & $9,7 \pm 1,1$ & $48,4 \pm 7,0$ & $48,9 \pm 5,8$ \\
A70t & $55,8 \pm 5,9$ & $55,2 \pm 5,4$ & $22,7 \pm 2,2$ & $22,6 \pm 2,1$ & $23,2 \pm 2,7$ & $22,8 \pm 2,6$ & $9,7 \pm 1,1$ & $9,6 \pm 1,0$ & $48,6 \pm 5,9$ & $48,4 \pm 5,0$ \\
B11nt & $55,9 \pm 5,7$ & $58,2 \pm 6,2 * *$ & $22,6 \pm 2,3$ & $22,3 \pm 2,0$ & $23,6 \pm 2,8$ & $25,7 \pm 3,5 * *$ & $9,65 \pm 1,3$ & $10,0 \pm 1,3^{*}$ & $48,1 \pm 6,3$ & $50,4 \pm 6,5^{*}$ \\
B11t & $53,6 \pm 7,0$ & $53,5 \pm 7,2$ & $21,4 \pm 3,2$ & $21,2 \pm 3,8$ & $21,6 \pm 4,2$ & $21,7 \pm 3,9$ & $10,5 \pm 1,9$ & $10,5 \pm 2,0$ & $52,6 \pm 9,6$ & $53,5 \pm 11,3$ \\
B70nt & $56,3 \pm 6,1$ & $58,7 \pm 6,4 * *$ & $22,8 \pm 3,0$ & $22,7 \pm 3,3$ & $23,5 \pm 3,0$ & $25,8 \pm 3,5 * *$ & $9,9 \pm 0,6$ & $10,1 \pm 0,6$ & $49,4 \pm 3,3$ & $50,7 \pm 3,1$ \\
B70t & $59,3 \pm 7,4$ & $59,3 \pm 7,4$ & $24,5 \pm 3,9$ & $24,7 \pm 3,7$ & $24,6 \pm 2,0$ & $24,5 \pm 3,5$ & $10,2 \pm 1,5$ & $10,1 \pm 1,4$ & $51,1 \pm 7,7$ & $50,7 \pm 7,2$ \\
\hline
\end{tabular}

Grupos: A- simulação; B- autoimplante esplênico; 11 - término do experimento no $11^{\circ}$ dia de pós-operatório; 70 - término do experimento no $70^{\circ}$ dia de pós-operatório; nt- não tratado com oxigênio hiperbárico; $t$ - tratado. * $p<0,05$ - do pré-operatório (Pré) para o pós-operatório (Pós) da VLDL-colesterol e triglicérides no grupo B11nt. ** p 0.01 -do pré-operatório para o pós-operatório do colesterol total, LDL-colesterol nos grupos B11nt e B70nt.

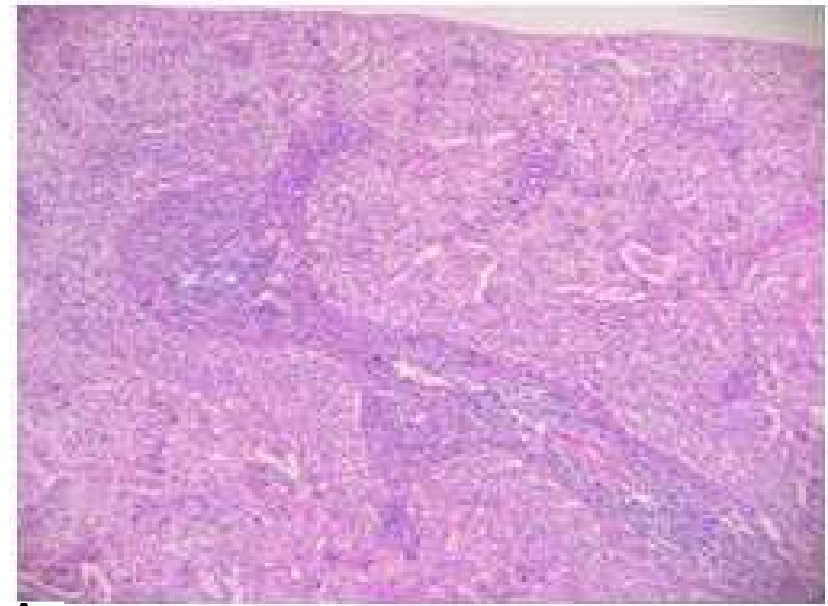

A

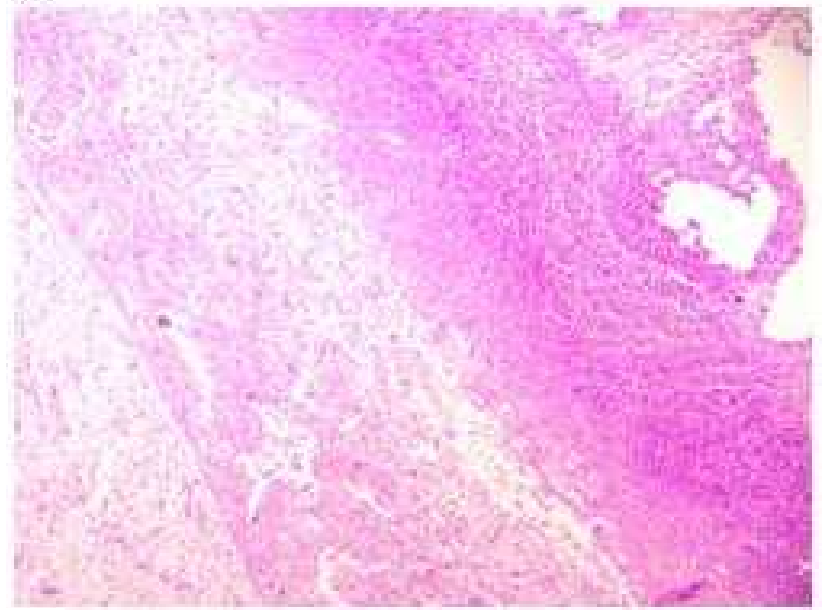

C

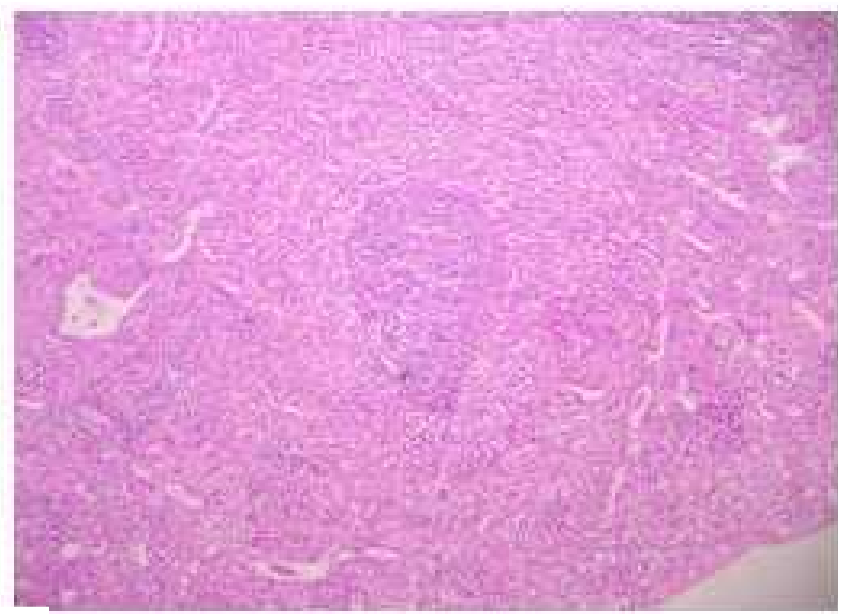

B

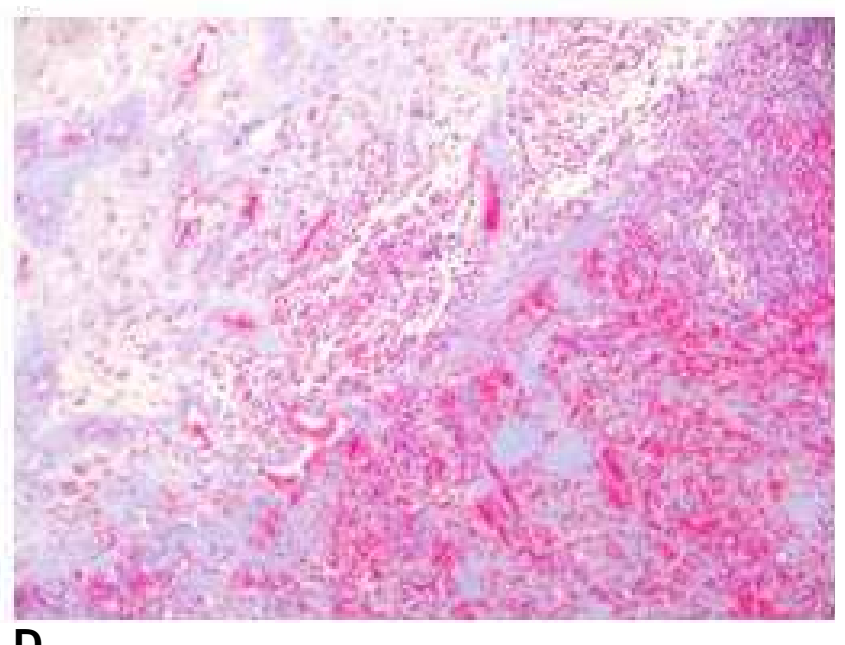

Figura 3 - Aspecto microscópico - $11^{\circ} \mathrm{PO}(\mathrm{POM})$. a) Grupo Simulação, não submetido à OHB. O aspecto microscópico é semelhante ao de um baço normal ( aumento 40 x HE); b) Grupo Simulação, submetido à OHB, com aspecto semelhante ao anterior (aumento 40 $x \mathrm{HE}$; c) Grupo auto-implante, não submetido à OHB. Observa-se necrose coagulativa subtotal (seta), intensa fibrose periesplênica, infiltração macrofágica centrípeta e áreas de atrofia acinar do pâncreas ( $40 \times \mathrm{HE}$ ); d) No grupo auto-implante com OHB observa-se fibrose, porém sem áreas de necrose coagulativa, com tecido periesplênico mais preservado (aumento $40 \times \mathrm{HE}$ ). 
preservado. No Grupo B70nt observou-se depleção linfocitária intensa das bainhas, hemossiderose, intensa fibrose periesplênica e intraparenquimatosa, sem esplenose periesplênica. No grupo B70t havia as mesmas alterações, porém de forma menos intensa do que no grupo não tratado (Figura 4).

\section{DISCUSSÃO}

A melhor viabilidade dos autoimplantes dos animais tratados com oxigênio hiperbárico ficou demonstrada principalmente no exame microscópico. Observou-se que as lesões do tipo necrose coagulativa e áreas de depleção linfóide desses remanescentes, em ambos os períodos de estudo, foram menos intensas nos animais tratados com oxigênio hiperbárico. As intensas aderências entre os autoimplantes e as alças intestinais, verificadas na época da retirada desses enxertos para exame histológico, dificultaram as dissecções. Esse fato dificultou muitas vezes as comparações macroscópicas entre os autoimplantes dos animais tratados e não tratados com oxigênio hiperbárico. Nos poucos casos em que foi possível fazer uma dissecção menos traumática desses enxertos, observou-se que o aspecto dos autoimplantes dos animais tratados apresentouse mais viável que o dos animais não tratados. Se considerarmos que a $\mathrm{OHB}$ apresenta efeito angiogênico, ${ }^{17,18}$ e que ela favorece a formação de circulação colateral ${ }^{19}$ além de

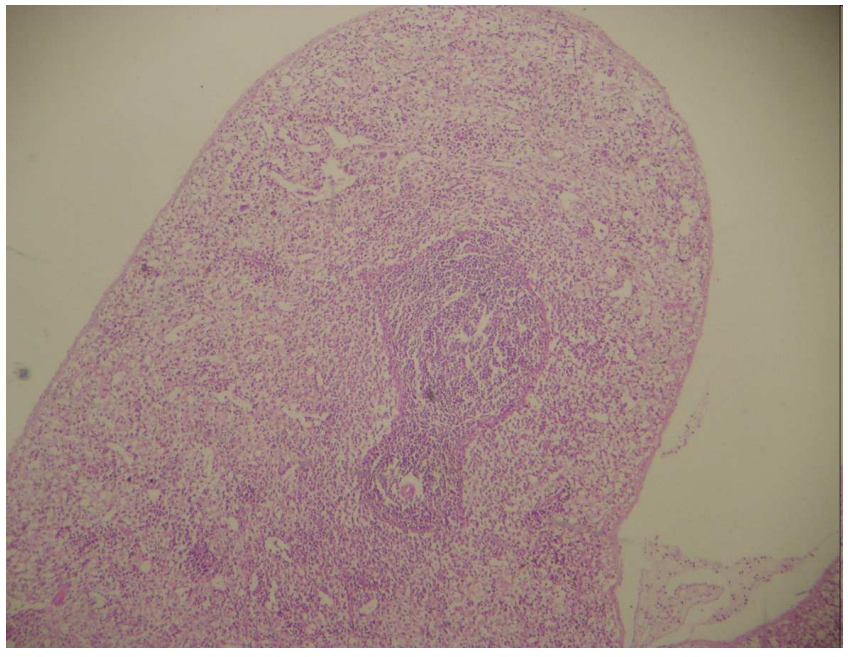

A

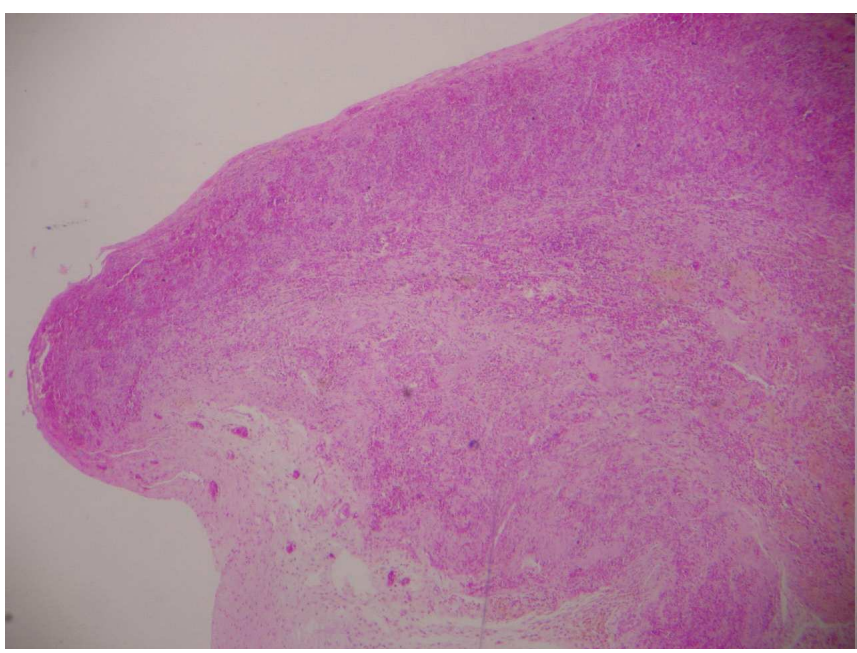

C

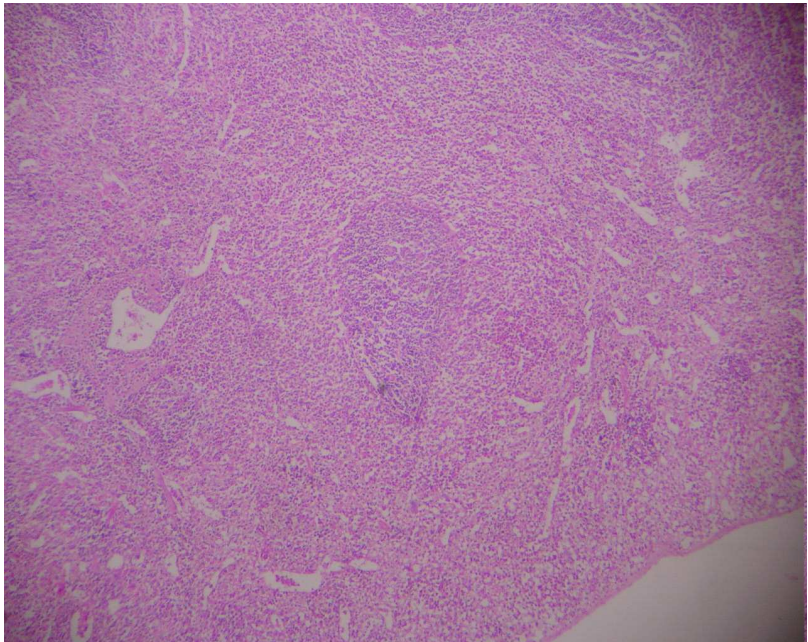

B

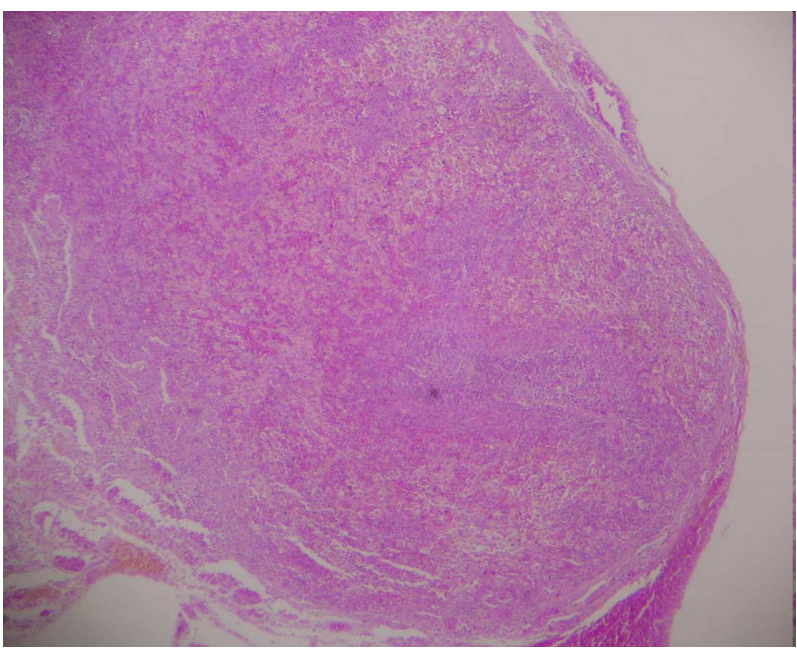

D

Figura 4 - $\quad$ Aspecto microscópico - $70^{\circ}$ PO (POT). a) Grupo simulação, não submetido à OHB. O aspecto microscópico é semelhante ao de um baço normal (aumento 40 x HE); b) Grupo simulação, submetido à OHB, com aspecto semelhante ao anterior (aumento 40 $x \mathrm{HE})$; c) Grupo auto-implante, não submetido à OHB. Observou-se depleção linfocitária intensa das bainhas, hemossiderose, intensa fibrose periesplênica e intraparenquimatosa, sem esplenose periesplênica (aumento 40 x HE); d) No grupo com OHB havia as mesmas alterações, porém de forma menos intensa do que no grupo sem OHB (aumento 40 x HE). 
diminuir o afluxo de neutrófilos para a área necrosada, ${ }^{31}$ é lógico admitir que ela tenha contribuído para melhorar a viabilidade dos autoimplantes esplênicos da mesma forma que contribuiu para melhorar a viabilidade do pólo inferior do baço ${ }^{30}$ e a pega de transplantes das ilhotas pancreáti$\operatorname{cas}^{20}$. Em ratos submetidos à ligadura das veias hepáticas, a OHB atenuou os efeitos deletérios e precoces sobre o fígado e o baço22.

A melhor função dos autoimplantes dos animais tratados com oxigênio hiperbárico foi observada principalmente no metabolismo lipídico. De fato, quando se comparam os níveis de lípides do grupo B11t com os do préoperatório ou os níveis do grupo B70t com os do pré-operatório, a diferença não é significante. Mas os níveis de lípides do grupo B1 1nt, principalmente, e do B70nt aumentaram significantemente em relação ao pré-operatório. Isso mostra que de fato a OHB evita aumento dos lípides não só no período mediato como também no período tardio. Essa proteção pode ser decorrente da melhor viabilidade dos enxertos conferida pela OHB, por uma ação antioxidante da $\mathrm{OHB}^{29}$ ou por ambos. A respeito da ação antioxidante, cumpre assinalar que a OHB em coelhos reduziu a progressão e acelerou a regressão da aterosclerose por mecanismo antioxidante ${ }^{29}$. Considerando que o LDL oxidado está implicado na gênese da referida doença, é possível que a OHB possa interferir nos níveis de LDL. Esse fato merece futuras investigações.

A função dos autoimplantes na produção de $\lg M$ foi deficiente em 11 dias e não sofreu influência da OHB. De fato, os animais tratados ou não com oxigênio hiperbárico apresentaram queda significante da IgM nesse período. As plaquetas aumentaram significantemente no $11^{\circ}$ dia de pós-operatório tanto nos animais tratados quanto nos animais não tratados. Esses resultados mostram que a $\mathrm{OHB}$ em período precoce não interfere na produção de lgM nem na depuração das plaquetas. No grupo 70 dias, nos animais tratados ou não com oxigênio hiperbárico, os níveis de lgM permanecem baixos, e o número de plaquetas não sofre alterações. Esses resultados fazem supor que a OHB não interfere nos níveis de lgM nem nos níveis de plaquetas nesse período tardio. Cumpre lembrar que no pós-operatório mediato das esplenectomias é comum observar-se aumento do número de plaquetas e que esse fato é revertido tardiamente sem nenhuma influência. Os animais com autoimplantes submetidos à $\mathrm{OHB}$ apresentam menor percentual dos corpúsculos de Howell-Jolly nos grupos 11 ou 70 dias que os animais não submetidos. Essa diferença se torna significante quando se faz a análise global dos casos. De fato, 19 animais submetidos à OHB apresentaram 32 corpúsculos, e 19 animais não submetidos apresentaram 73 corpúsculos $(p=0,03)$. Esses resultados mostram que a $\mathrm{OHB}$ em animais com autoimplantes no $70^{\circ}$ dia de pós-operatório não interfere na síntese de imunoglobulinas, mas contribui para depurar os corpúsculos de Howell-Jolly, o que sugere uma melhor função esplênica.

Neste trabalho cumpre destacar que o percentual de autoimplante foi de $49 \%$, que a análise no pós-operatório tardio foi feita no $70^{\circ}$ dia, que a OHB foi feita em 10 dias e que foram estudadas algumas funções do baço. Por esses motivos seriam interessantes outros estudos utilizando-se outros protocolos de OHB, avaliando-se outras funções esplênicas, com a utilização de outros percentuais de massa esplênica.

Em conclusão, os animais com autoimplantes esplênicos tratados com oxigênio hiperbárico apresentaram melhor função e viabilidade do que os animais com autoimplantes não-tratados.

\section{Agradecimentos}

Ao Departamento de Apoio à Pesquisa Clínica e Experimental do Instituto de Desenvolvimento de Ações Práticas e Procedimentos na área de Saúde, pelo apoio financeiro.

\section{A $B$ S $S$ T R A C T}

Objective: To study the functional and morphological features of splenic autoimplants in rats subjected, or not, to postoperative hyperbaric oxygen therapy. Methods: One hundred and five male Wistar rats, weighing $251.6 \mathrm{~g} \pm 29.5 \mathrm{~g}$, were studied ot early (11th day) and late (70th day) postoperative periods. For each period the animals were distributed in the following groups: $A$ $(n=40)$, splenic manipulation; $B(n=65)$, splenic autoimplants, not treated (nt) (A11nt- $n=10, B 11 n t-n=21$, A70nt- $n=10, B 70 n t-n=$ 18) and treated with hyperbaric oxygen ( $t)$ ( A11t- $n=10, B 11 t-n=15, A 70 t-n=10, B 70 t-n=11)$. Blood was collected for measurement of lipids and immunoglobulins, platelet and Howell-Jolly body count before and after surgery. The spleen and autoimplants were removed for histologic analyses. Results: There was an increase of total cholesterol $(p=0.00068), L D L-$ cholesterol $(p=0.002), V L D L$-cholesterol and triglycerides $(p=0.0033)$ in B11nt group. There was an increase of total cholesterol $(p=0.0007)$ and LDL-cholesterol $(p=0.0000)$ in B70nt group, and no alterations were observed in the other groups. IgM decreased in B groups $(p=0.0000)$ and no changes were observed in the splenic manipulation group. Number of Howell-Jolly bodies were lesser in Bt groups than in Bnt groups $(p=0.03)$. Platelets were increased in B11t and B11nt groups $(p=0.0000)$ and remained unchanged in the other groups. Autoimplants microscopic viability was better in Bt groups than in Bnt. Conclusion: The splenic autoimplants of rats treated with hyperbaric oxygen therapy showed a better functionality and viability than those subjected to other procedures.

Key words: Spleen/surgery. Spleen/metabolism. Splenectomy/methods. Splenectomy/adverse effects. Hyperbaric oxygenation. 


\section{REFERÊNCIAS}

1. Petrovic M, Popovic M, Knezevic S, Matic S, Gotic M, Milovanovic A et al. [Intraoperative and postoperative complications of splenectomy]. Acta Chir lugosl. 2002; 49(3): 81-4

2. King H, Shumacker Jr HB. Splenic studies. Ann Surg.1952; 136 : 239-42.

3. Marques RG, Petroianu A. Overwhelming postsplenectomy infection. Arq. Gastroenterol. 2003; 40(1): 47-54.

4. Andersson R, Alwmark A, Bengmark S. Outcome of pneumococcal challenge in rats after splenic artery ligation or splenectomy. Acta Chir Scand. 1986; 152: 15-7

5. Aviram M, Brook JG, Tatarsky, Levy Y, Carter A. Increased lowdensity lipoprotein levels after splenectomy: a role for the spleen in cholesterol metabolism in myeloproliferative disorders. Am J Med Sci. 1986; 291(1): 25-8.

6. Sugihara T, Yawata Y. Observations on plasma and red cell lipids in hereditary spherocytosis. Clin Chim Acta. 1984; 137(2): 227-32.

7. Asai K, Kuzuya M, Naito M, Funaki C, Kuzuya F. Effects of splenectomy on serum lipids and experimental atherosclerosis. Angiology. 1988; 39(6): 497-504.

8. Fatouros M, Bourantas K, Bairaktari E, Elisaf M, Tsolas O, Cassioumis. Role of the spleen in lipid metabolism. Br J Surg. 1995; 82(12): 1675-77.

9. Paulo DNS, Lázaro da Silva A. Lipídios plasmáticos após esplenectomia total e parcial em cães. Rev Col Bras Cir. 2001; 28(2): 264-70.

10. Silva MM, Jamel N, Refinetti RA, Oliveira MAS, Padilha MS. Papel do baço no perfil lipídico. Estudo Experimental. Arq Bras Cir Dig. 2002; 15(1): 121-4

11. Paulo ICAL, Paulo DNS, Lázaro da Silva A, Foletto RM, Colnago GL, Vargas PM. Níveis de lípides plasmáticos em ratos submetidos á esplenectomia total, ligadura simultânea dos vasos esplênicos e à esplenectomia subtotal. Rev Col Bras Cir. 2005; 32(1): 229-36.

12. Jamel MJ, Refineti RA, Silva MM, Maciel ACC, Marelli GB. Papel do remanescente esplênico no perfil lipídico. Arq Bras Cir Dig. 2002; 15(1): 105-7.

13. Petroianu A, Veloso DFM, Costa GR, Alberti LR. Effects of splenic surgeries on lipidogram of rats. Rev Ass Med Bras. 2006; 52(1): 569.

14. Linuma H, Okinaga K, Sato S, Tomioka M, Matsumoto K. Optimal site and amount of splenic tissue for autotransplantation. J Surg Res. 1992; 53(2): 109-16

15. Conselho Federal de Medicina. Resolução no 1457 de 15 de setembro de 1995. Conselho Federal de Medicina. Diário Oficial da União. Brasília, 19 de setembro de 1995.

16. D'Agostino Dias M, Fontes B, Poggetti RS, Birolini D. Hyperbaric oxygen therapy: types of injury and number of sessions - a review of 1506 cases. Undersea Hyperb Med. 2008; 35(1): 53-60.

17. Muhonen A, Haaparanta M, Grönroos T, Bergman J, Knuuti J, Hinkka S, Happonen RP. Osteoblastic activity and neoangiogenesis in distracted bone of irradiated rabbit mandible with or without hyperbaric oxygen treatment. Int J Oral Maxillofac Surg. 2004; 33(2): $173-8$

18. Cundall JD, Gardiner A, Chin K, Laden G, Grout P, Duthie G. Hyperbaric oxygen in the treatment fecal incontinence secondary to pudendal neuropathy. Dis Colon Rectum. 2003; 46(11): 154954.
19. Burt JT, Kapp JP, Smith RR. Hyperbaric oxygen and cerebral infarction in the gerbil. Surg Neurol. 1987; 28(4): 265-8.

20. Juang JH, Hsu BR, Kuo CH, Uengt SW. Beneficial effects of hyperbaric oxygen therapy on islet transplantation. Cell Transplant. 2002; 11(2): 95-101.

21. Paulo DNS, Kalil M, Grillo Júnior LSP, Borges EB, Cintra LC, Pereira FEL, Lázaro da Silva A. Viabilidade do baço após a ligadura dos vasos esplênicos: efeito do tratamento com oxigênio hiperbárico. Rev Assoc Med Bras. 2005; 51(1): 46-50.

22. Costa-Val R, Nunes TA, Oliveira e Silva RC, Souza TKP. Efeitos da oxigenoterapia hiperbárica em ratos submetidos à ligadura das veias hepáticas: avaliação da mortalidade e da histologia do fígado e baço. Acta Cir Bras. 2006; 21(1): 52-7.

23. Mas N, Isik AT, Mas MR, Comert B, Tasci I, Deveci S et al. Hyperbaric oxygen-induced changes in bacterial translocation and acinar ultrastructure in rat acute necrotizing pancreatitis. J Gastroenterol. 2005; 40(10): 980-6.

24. Yasar M, Yildiz S, Mas R, Dundar K, Yildirim A, Korkmaz A et al . The effect of hyperbaric oxygen treatment on oxidative stress in experimental acute necrotizing pancreatitis. Physiol Res. 2003; 52(1): 111-6

25. Cheng HM, Shyr MH, Ueng SW, Chen MF. Hyperbaric oxygen therapy attenuates pancreatic microcirculatory derangement and lung edema in an acute experimental pancreatitis model in rats. Pancreas. 1998; 17(1): 44-9.

26. Akin ML, Gulluoglu BM, Uluutku H, Erenoglu C, Elbuken E, Yildirim $S$, Celenk T. Hyperbaric oxygen improves healing in experimental rat colitis. Undersea Hyperb Med. 2002; 29(4): 279-85.

27. Rachmilewitz D, Karmeli F, Okon E, Rubenstein I, Better OS Hyperbaric oxygen: a novel modality to ameliorate experimental colitis. Gut. 1998; 43(4): 512-8.

28. Liu W, Zhao W, Lu X, Zheng X, Luo C. Clinical pathological study of treatment of chronic hepatitis with hyperbaric oxygenation. Clin Med J. 2002; 115(8): 1153-7.

29. Kudchodkar BJ, Wilson J, Lacko A, Dory L. Hyperbaric oxygen reduces the progression and accelerates the regression of atherosclerosis in rabbits. Arterioscler Thromb Vasc Biol. 2000; 20(6): 1637-43

30. Paulo ICAL, Paulo DNS, Ferrari TA, Azeredo TCV, Lázaro da Silva A. O pólo inferior do baço de ratos e a oxigenoterapia hiperbárica. Rev Assoc Med Bras. 2008; 54(1): 77-81.

31. Miljkovic-Lolic M, Silbergleit R, Fiskum G, Rosenthal RE. Neuroprotective effects of hyperbaric oxygen treatment in experimental focal cerebral ischemia are ssociated with reduced brain leukocyte myeloperoxidase activity. Brain Res. 2003; 971(1): 90-4

Recebido em 26/03/2009

Aceito para publicação em 01/06/2009

Conflito de interesse: nenhum

Fonte de financiamento: nenhuma

\section{Como citar este artigo:}

Paulo ICA, Silva AL, Piras C, Ramos BF, Zanetti FR, Paulo DNS Autoimplante esplênico e oxigenoterapia hiperbárica em ratos. Rev Col Bras Cir. [periódico na Internet] 2010; 37(3). Disponível em URL: http://www.scielo.br/rcbc

Endereço para correspondência:

Isabel Cristina Andreatta Lemos Paulo

E-mails: icpaulo@santacasavitoria.org, isabel.paulo@emescam.br 